\title{
Geotechnical laboratory testing and data interpretation for biosolids and sewage sludge
}

Brendan C. O’Kelly PhD, FTCD, CEnv, CEng, MICE

Associate Professor, Department of Civil, Structural and Environmental

Engineering, Trinity College Dublin, Dublin, Ireland (bokelly@tcd.ie)

(Orcid:0000-0002-1343-4428)

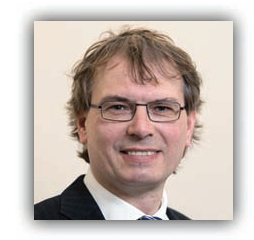

Biosolids and sewage sludge are difficult, challenging and unconventional geomaterials with some distinctive properties, including extremely high water content and plasticity; low particle density; high organic content; very high compressibility, creep and strain rate dependence of strength; a viscous gel-like pore fluid phase; extremely low permeability coefficient; and a propensity to degrade, producing copious amounts of biogas. The geotechnical properties and behaviour of these materials have been comprehensively reviewed in a companion paper previously published in this journal. The purpose of the present review paper is to describe necessary procedural modifications to standard geotechnical laboratory test methods, including associated analyses and data interpretation procedures, to obtain meaningful determinations of their index, compaction, compression, consolidation and permeability properties and their undrained and effective-stress strength parameter values. Specific aspects investigated include a modified curve-fitting technique for interpreting oedometer strain-time data, rapid and accurate means for undrained strength measurement and the significance and effects of ongoing biodegradation for long-term tests, as well as the corrosive nature of these materials. Many of the procedural modifications to geotechnical laboratory testing and nuances in the data interpretation presented in this paper should be transferable to the testing of other biodegradable soil and soil-like materials.

\author{
Notation \\ $A, B \quad$ pore pressure coefficients \\ $C^{\prime} \quad$ cohesion intercept (effective stress) \\ $c_{\text {DSS }}^{\prime} \quad$ cohesion intercept from direct simple shear testing \\ $c_{\mathrm{TC}}^{\prime} \quad$ cohesion intercept from triaxial compression testing \\ $c_{\mathrm{v}} \quad$ coefficient of consolidation \\ e void ratio \\ $h \quad$ cone penetration depth \\ $K \quad$ cone factor \\ $k \quad$ permeability coefficient \\ $m_{\mathrm{v}} \quad$ coefficient of volume compressibility \\ $N \quad$ loss in dry mass on ignition \\ $S_{\mathrm{C}} \quad$ solids content \\ $S_{\mathrm{r}} \quad$ degree of saturation \\ $s_{\mathrm{u}} \quad$ undrained shear strength \\ $t \quad$ elapsed time \\ $t_{50}$ time period corresponding to $50 \%$ of the \\ consolidation strain \\ $t_{90}$ time period corresponding to $90 \%$ of the \\ consolidation strain \\ $U$ average degree of consolidation
}

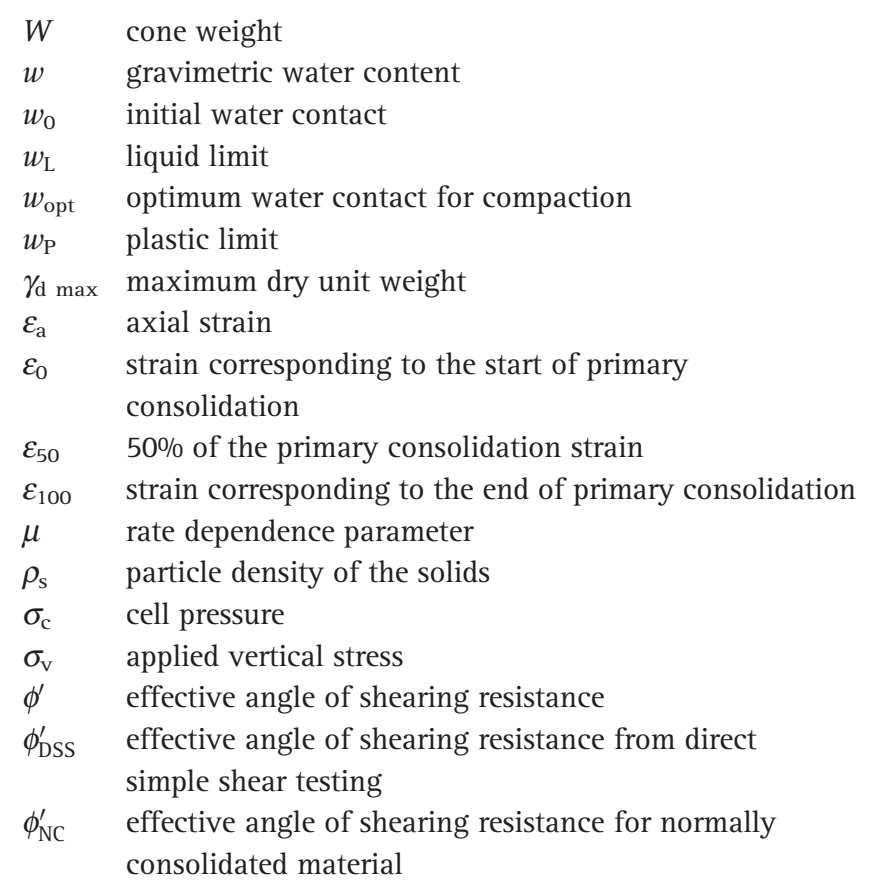




\section{$\phi_{\mathrm{TC}}^{\prime} \quad$ effective angle of shearing resistance from triaxial compression testing \\ $\phi_{\mathrm{u}} \quad$ undrained angle of shearing resistance}

\section{Introduction}

Biosolid and sewage sludge materials are the highly organic residue by-products of wastewater treatment processes. Their organic fractions principally originate from human faeces (primary sludge) and bacterial biomass (secondary sludge), with their inorganic fractions derived from materials such as soil, sediment and inorganic residuals (O'Kelly, 2016a). Sewage sludge refers to the slurry material separated out during the primary and secondary treatment processes. Biosolids refer to treated sewage sludge materials that meet regulatory pollutant- and pathogencontrol requirements for land application and surface disposal.

The amounts of these materials being annually produced worldwide have increased dramatically over recent years because of population growth, urbanisation and stricter regulations on the quality of wastewater discharges which require new treatment plants and continuous upgrading of existing facilities. At the treatment works, these slurry residue streams are dewatered using filter presses, centrifuges, belt-dryer machines or other technologies (after chemical conditioning of the residue by-product) and (or) solar drying of the caked solids in sludge drying beds, typically lowering the gravimetric water content to a few hundred per cent (Metcalf \& Eddy, 2004; O'Kelly and Quille, 2009).

The dewatered and (or) solar-dried materials are disposed of by various means, including: their beneficial uses as agricultural fertilisers, in forestry, for composting and soil redevelopment and in mine reclamation; their indefinite storage in single-purpose disposal pits or lagoons; landfilling at dedicated deposition areas or co-disposal with municipal solid waste at sanitary landfills or dedicated monofills; and incineration (O'Kelly, 2016a). In limited circumstances, biosolids and sewage sludge amended with additives such as lime, fly ash, cement or slag can be used as construction materials - for example as landfill cover (Chen et al., 2014) or as structural fill material in road embankments (Arulrajah et al., 2013), with special protection required in the event that there is potential leaching (flow) to adjoining water bodies.

Hence, knowledge of the environmental and geotechnical properties of the biosolid and sewage sludge materials is of central importance (Johnston and O'Kelly, 2016). Studies on the biochemical properties of their organic solids (i.e. carbohydrates, proteins and lipids), leachate (copper, nickel, zinc and calcium concentrations and dissolved organic carbon) and gas phases were reported by Arulrajah et al. (2011), Disfani et al. (2013), Kayser (2012), Kayser et al. (2015) and O'Kelly (2018a).

The geotechnical properties and behaviour of biosolid and sewage sludge materials have been comprehensively reviewed by O'Kelly (2016a). In summary, compared with most inorganic fine-grained soils, dewatered biosolid and sewage sludge materials typically have extremely high water content, high organic content, extremely high plasticity, low particle density and, hence, low bulk and dry unit weights. Further, these materials typically have very high compression, swelling and shrinkage potentials, low undrained strength, high strain rate dependence of strength, strong thixotropic behaviour, extremely low coefficients of consolidation and permeability values (O'Kelly, 2016a), with a propensity to degrade and produce copious volumes of biogas for $\mathrm{pH}<11$ (Kayser et al., 2011). The composition and viscosity of the pore fluid phase also change over time, with the generation of new microbial cells, fatty acids and polymers (O’Kelly, 2013a).

For dried biosolid and sewage sludge materials, the soil structure alters significantly during the drying process, with the solid particle aggregates clumping together, forming peds (O'Kelly, 2016a, 2016b). Permanent material changes occur on account of the biodegradation and oxidation processes, which have the effects of (Diliūnas et al., 2010; O'Kelly, 2005a, 2006a, 2008a, 2016b; Zhan et al., 2014) (a) changing the compositions and properties of the solid and pore fluid phases; $(b)$ reducing the solid mass (volume) due to the resulting loss of susceptible organic matter; (c) significantly reducing the materials' plasticity; $(d)$ increasing the particle density and, hence, the bulk and dry unit weights achieved (assuming the biogas produced internally can escape); and $(e)$ reducing the optimum water content for compaction $\left(w_{\text {opt }}\right)$ and increasing the maximum dry unit weight $\left(\gamma_{\mathrm{d}} \max \right)$ values achievable. When the generated biogas remains trapped within the bulk mass, the pore fluid pressure builds up over time, producing reductions in the effective confinement pressure, consolidation rate and shear strength (O'Kelly, 2005a, 2006a, 2013b).

The degradation and reduction in the organic matter content, which typically has an extremely high water-holding capacity, correlates with reductions in the materials' natural water content and void ratio values (O'Kelly, 2016a; Zhan et al., 2014). In other words, the compositions and engineering properties and behaviour of the biosolid and sewage sludge materials can change significantly over time, with the rates and intensities of these changes largely governed by the prevailing geoenvironmental conditions (Diliūnas et al., 2010; O’Kelly, 2005a, 2006a, 2018a).

Other distinctive features of these materials are their microstructures (with a significant proportion of the solid 'particles' (flocs) composed of aggregated clay-sized organic particles that contain significant volumes of interstitial fluid (O'Kelly, 2013a)) and the complex compositions of their non-Newtonian pore fluids. The latter behaviour arises on account of their viscous gel-like nature resulting from the high concentrations of suspended and dissolved solids, high bonding or adsorption of the liquid phase within and around the aggregate flocs and some form of biological coagulation between the pore fluid and the organic solids (Klein and Sarsby, 2000; O’Kelly, 2008a, 2016b; Sarsby, 2005).

The purpose of this review paper is to consolidate the current understanding of geotechnical laboratory testing for these difficult, 
challenging and unconventional geomaterials. Necessary procedural modifications to the standard test methods, including associated analyses and data interpretation procedures, are described, in order to arrive at accurate and meaningful determinations of their index, compaction, compression, consolidation and permeability properties and their undrained shear strength $\left(s_{\mathrm{u}}\right)$ and effective-stress strength parameter $\left(c^{\prime}, \phi^{\prime}\right)$ values.

Since the dewatered biosolid and sewage sludge materials are soil-like, their behaviours in disposal pits and lagoons, monofills and sanitary landfills can assessed with reasonable accuracy by using soil mechanics theory and conventional in situ and geotechnical laboratory testing provided that due care and attention are given to their distinctive properties. Hence, this paper has practical values for further studies and engineering projects related to the disposal or reuse of biosolid and sewage sludge materials. For instance, geotechnical index properties are used for soil classification and can be correlated with useful design parameters (O'Kelly et al., 2018b). Knowledge of the compression, consolidation and permeability properties is important in that the compression magnitude and consolidation rate determine the reductions in the water content and void ratio values and, hence, the increases in strength and stability of the engineered landfill body. Shear strength governs the economics of successful land remediation and landfill or monofill operations - for example, it determines the slope gradients possible as well as the machine plant that can be employed in their construction. Rapid and accurate strength-measurement techniques are often needed in practice; for instance, when dewatered material for landfilling has been transported in bulk to reach the landfill gate, the landfill operator needs to confirm from a geotechnical standpoint that the material meets minimum strength requirements before accepting the material for disposal on-site.

For comprehensive information on the geotechnical properties and pertinent parameter values of dewatered and compacted biosolid and sewage sludge materials, the reader is referred to the companion paper by the author (O'Kelly, 2016a). Recommendations on the placement and compaction of the biosolid material in a monofill facility, along with guidance on the selection of design strength values for geotechnical stability analyses and in performing settlement calculations, are presented by O'Kelly (2004a, 2005b), with a biosolid-monofill case study presented by O'Kelly et al. (2018b).

\section{Soil classification and compaction testing}

Water content determination

The water content parameter, which is used in the geotechnical literature and also for the purposes of this paper, is defined as the mass of the pore fluid to the mass of the dry solids, expressed as a percentage. The solids content $\left(S_{\mathrm{C}}, \%\right)$, used in some other fields and defined as the mass of the dry solids to the bulk mass, is related to the water content $(w, \%)$ by the equation

$$
\text { 1. } S_{\mathrm{C}}: \%=\frac{100}{1+w / 100}
$$

For water content determinations on organic soils, some charring, oxidation and (or) vaporisation of susceptible organic matter may occur for the standardised oven-drying temperature ranges of $110 \pm 5^{\circ} \mathrm{C}$ (ASTM, 2010) and $105-110^{\circ} \mathrm{C}$ (BSI, 1990a) specified for the testing of inorganic soils. The ensuing loss in the dry solids mass of the test specimen, which is incorrectly interpreted as evaporation of pore fluid from the viewpoint of performing the water content calculation, results in values apparently higher than the correct water content value.

From oven-drying investigations on biosolid and sewage sludge materials, O'Kelly $(2005$ c, 2014) and O'Kelly and Sivakumar (2014) concluded that oven drying at $105-110^{\circ} \mathrm{C}$, in conjunction with a $24 \mathrm{~h}$ drying period and a minimum wet specimen mass of $50 \mathrm{~g}$, is acceptable (and preferable to using lower over-drying temperature values) for routine water content determinations on these materials. This is consistent with the ASTM (2014) and US Environmental Protection Agency (USEPA, 2001) standards and also with the recommendations for water content determinations on peat materials presented in the papers by Hobbs (1986) and Skempton and Petley (1970). For instance, from experimental investigations of the oven-drying characteristics of sewage sludge material ( $N=70 \%$; where $N$ is the loss in dry mass on ignition) for the temperature range of $60-150^{\circ} \mathrm{C}$, O'Kelly (2005c) deduced that $86^{\circ} \mathrm{C}$ was the correct oven-drying temperature for water content determinations on this material, but that the resulting error from using an oven temperature of $105-110^{\circ} \mathrm{C}$ was acceptable for routine water content determinations.

Oven-drying temperatures in the range of $60-90^{\circ} \mathrm{C}$ are still routinely used in some commercial and research laboratories for water content determinations on organic soils. It is recommended, however, that values of water content corresponding to the pertinent standardised oven-drying temperature range be deduced from these measured water content values by using the methods presented in the papers by O'Kelly (2005d) and Skempton and Petley (1970).

\section{Particle-size distribution}

Various challenges encountered in performing wet sieve and sedimentation (hydrometer) testing for the determination of the particle-size distribution (PSD) of biosolid and sewage sludge materials are discussed by Kayser (2012) and O'Kelly (2016b). For instance, with these materials composed of flocs of clay and silt-sized particles having high organic matter content, the question invariably arises as to what constitutes an individual solid particle for the purposes of determining the grading curve.

Another complication is that reported grading curves for air-dried biosolid and sewage sludge material samples (either prepared in the 
laboratory or sourced from sludge drying beds, evaporation lagoons or material stockpiles) often suggest that these materials are sandy silt (Arulrajah et al., 2013; GLSEC, 2003) or very gravelly sand soils (Stone et al., 1998) (see range of PSDs in Figure 1). This misclassification based on the obtained grading curves can be explained by insufficient disaggregation of the cohesive soil clumps in preparing the test materials for PSD analyses (O'Kelly, 2016a).

As such, Kayser (2012) reported laser diffraction analysis as an alternative approach for sedimentation testing for the determination of the PSD (but based on the volume rather than the dry mass of material passing) of the fine portion of biosolid and sewage sludge materials. The test specimens are prepared with a dispersion agent, allowed to soak and then placed in an ultrasonic bath for a $1 \mathrm{~h}$ period with frequent stirring, which was found to be more effective in disaggregating the particle flocs.

\section{Atterberg limits and soil classification}

The compositions and properties of biosolid and sewage sludge materials derived from different sources, wastewater treatment methods and geographical regions can be significantly different (Arulrajah et al., 2011; O'Kelly, 2006a, 2016a). For instance, young biosolid and sewage sludge materials typically have very high total volatile solid $(N)$ values, ranging from approximately 40 to $70 \%$ (O'Kelly, 2016a), which explains their extremely high water content and plasticity.

The compositions and properties of these materials can also change significantly over time on account of biodegradation and oxidation processes. For instance, solar drying of dewatered biosolid and sewage sludge materials in sludge drying beds, evaporation lagoons or stockpiles is generally accompanied by significant reductions in their organic contents, with the $N$ values of aged biosolid materials typically ranging from 6\% (stockpiled for more than 12 years) to $40 \%$ (O'Kelly, 2016a). The substantial reduction in the organic content and also the changing nature of the organic solids are accompanied by substantial reductions in material plasticity and, hence, in the values of the liquid limit, plastic limit and plasticity index values (O'Kelly, 2016a). Similar transformational behaviour occurs with the drying (oxidation) of peat materials (O'Kelly and Pichan, 2013).

As such, the Atterberg limits provide some guidance regarding other geotechnical properties and the degree of biodegradation. For instance, in the extended plasticity chart presented in Figure 2(b), the dewatered biosolid and sewage sludge materials invariably plot above the A-line and are classified as organic clay of extremely high plasticity. Air-dried test materials and solardried materials sampled from drying beds, evaporation lagoons and stockpiles have undergone significant reductions in their plasticity. Hence, these materials generally plot below the A-line (see Figure 2(a)) and are usually classified as organic silt of intermediate to extremely high plasticity (O'Kelly, 2016a).

For wet biosolid and sewage sludge materials, the Atterberg tests are performed on the soil fraction passing a $425 \mu \mathrm{m}$ sieve (obtained using the wet sample preparation technique) or on the material in its natural condition. In other words, air-drying and

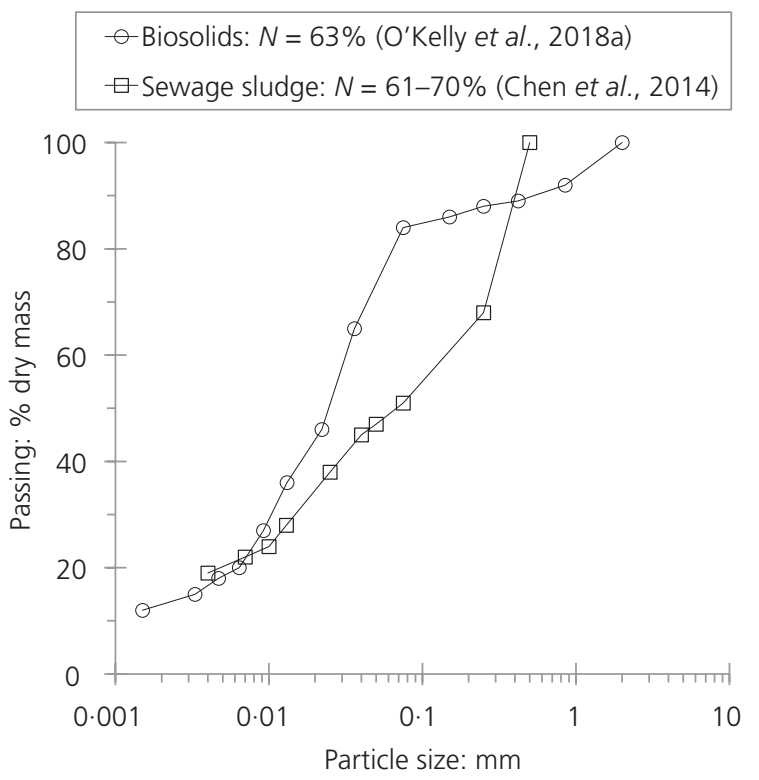

(a)

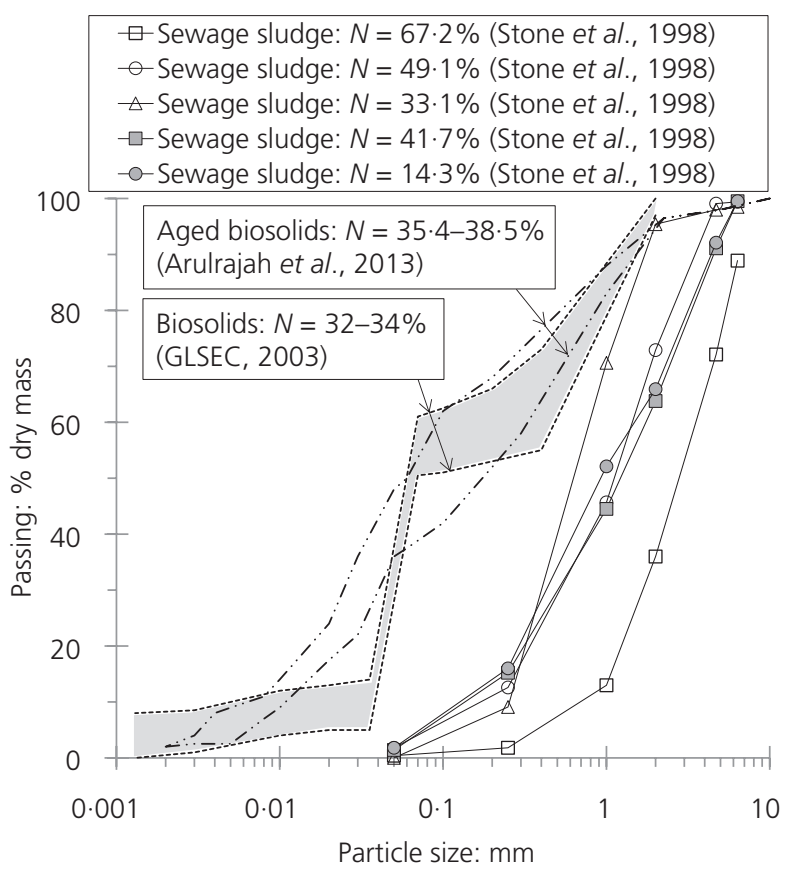

(b)

Figure 1. PSD curves for various biosolid and sewage sludge materials: (a) dewatered condition; (b) solar-dried condition from stockpiles or evaporation beds and lagoons (adapted from O'Kelly (2016a)) 


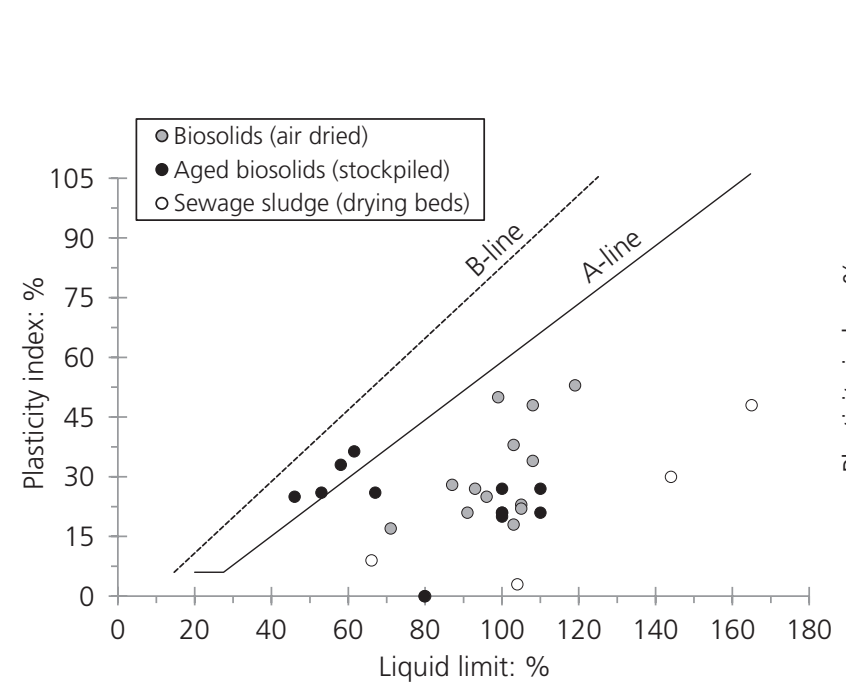

(a)

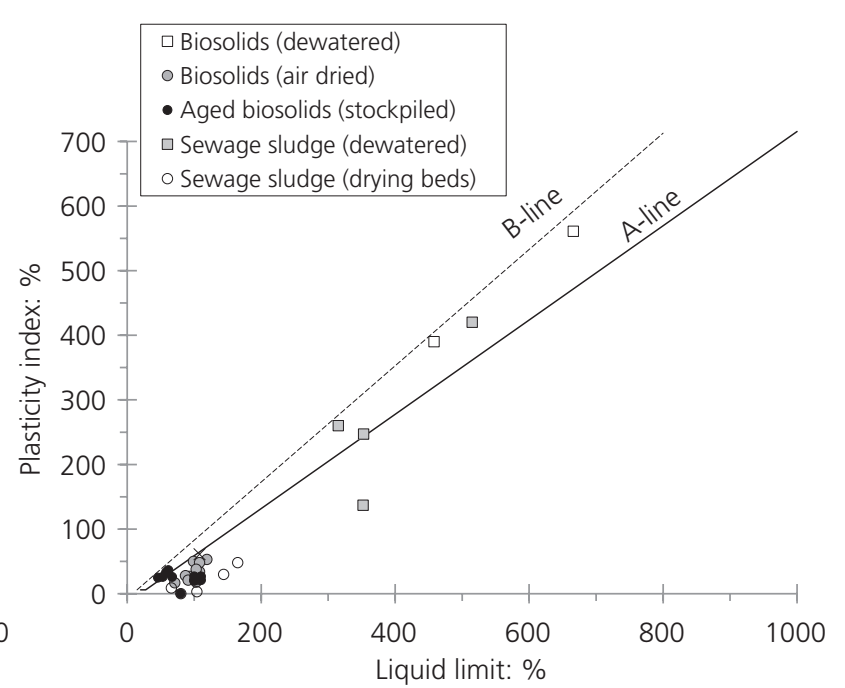

(b)

Figure 2. Soil classification: (a) standard plasticity chart; (b) extended plasticity chart (adapted from O'Kelly (2016a))

(or) oven drying of the sampled materials during the specimen preparation process would result in significantly lower measured consistency limit values and much narrower plastic ranges that are not representative of the original materials.

O’Kelly (2015a, 2016c) describes fundamental issues regarding the appropriateness of the Atterberg limit concepts applied to organic soils. Water content and organic content (along with fibre content and degree of humification in the case of peat materials) are advocated as a more useful suite of index tests for assessments of the likely engineering behaviours of highly organic soils (O'Kelly, 2015a, 2016c). For instance, organic content (determined from the loss-on-ignition test) has a useful relationship with the particle density of the solids, as described in the next section, and it can also be used for an assessment of the degree of biodegradation in the case of biosolid and sewage sludge materials. However, these materials have negligible fibrosity compared with fibrous peats (e.g. see O'Kelly and Pichan (2013)) - that is, they have no significant fibre reinforcement effect present (O'Kelly, 2013a).

\section{Particle density and organic content}

Compared with inorganic soils, particle density $\left(\rho_{\mathrm{s}}\right)$ testing of biosolid and sewage sludge materials by using the small pycnometer method (definitive method) is more challenging. Nevertheless, accurate measurements can be obtained for thoroughly pulverised test material, with kerosene or white spirits used instead of distilled water as the saturating liquid in the density bottles (O'Kelly, 2005e, 2018a). Since peds of these materials become extremely strong and stiff on drying, the use of a mortar and pestle to pulverise the dry peds in preparing the test specimens becomes incredibly difficult. As such, a ring mill or coffee grinder (as used in a rapid soil analysis kit) can be employed for this purpose, if necessary (O'Kelly, 2018a).
The use of kerosene (or white spirits) as the saturating liquid prevents biodegradation of susceptible organic solids during the course of performing the particle density tests, which would otherwise have the effect of producing an overestimation of the $\rho_{\mathrm{s}}$ value compared to the original material (O'Kelly, 2018a). Further, a shorter vacuum period of $16-24 \mathrm{~h}$ is usually adequate to achieve complete degassing of the submerged test specimens with kerosene as the saturation liquid (O'Kelly, 1994).

Ongoing biodegradation of biosolids and sewage sludge reduces their solid mass (volume) due to the loss of susceptible organic matter, as reflected by the reductions in their $N$ values and the increases in their $\rho_{\mathrm{s}}$ values (Diliūnas et al., 2010; O'Kelly 2006a, 2008a; Zhan et al., 2014). For instance, lightly and strongly degraded sewage sludge materials typically have $N$ values of approximately 70 and $55 \%$, respectively, with this $N$ value reduction corresponding to a $33 \%$ reduction in the dry solids' mass (O'Kelly, 2005a). If the increase in the $\rho_{\mathrm{s}}$ value for higher states of biodegradation is not accounted for in mass-volume relation calculations for biosolid and sewage sludge materials, the knock-on effect is an overestimation of the degree of saturation $\left(S_{\mathrm{r}}\right)$ and an underestimation of the gas voids content values (O’Kelly, 2013a, 2018a).

The organic content of soil is generally evaluated indirectly as the $N$ value determined using the loss-on-ignition test. For practical purposes, $N$ value measurements for biosolid and sewage sludge materials based on the specimen oven-drying temperature range of $105-110^{\circ} \mathrm{C}$ (ASTM, 2014) and an ignition temperature of $440 \pm$ $25^{\circ} \mathrm{C}$ (ASTM, 2014; BSI, 1990b) are equivalent to the organic content value for $N>10 \%$ (O'Kelly, 2018a). It is recommended that the lower oven-drying temperature range of $50 \pm 2 \cdot 5^{\circ} \mathrm{C}$ specified in BSI (1990b) and higher ignition temperatures (e.g. 550 or $800^{\circ} \mathrm{C}$ ) sometimes employed in practice should not be 
used for the testing of these materials since they result in an overestimation of their organic content values (O'Kelly, 2018a). In other words, significant amounts of residual pore fluid remain in the oven-dried specimens for this lower oven-drying temperature range (O'Kelly, 2004b, 2005d; Skempton and Petley, 1970) and unintentional losses in the inorganic solid mass occur for the higher ignition temperatures.

Since the pycnometer test method is tedious and time consuming, the particle density value of a soil is often determined by correlation with its loss on ignition, which arguably is a more straightforward test to perform and has greater reliability. Using the correlation presented in Figure 3, the $\rho_{\mathrm{s}}$ values of different biosolid and sewage sludge materials can be determined indirectly from their measured $N$ values, with typical $\rho_{\mathrm{s}}$ values of the inorganic and organic solid fractions of these materials determined as 2.65 and $1 \cdot 30$, respectively (O'Kelly, 2018a). As evident from this figure, the $\rho_{\mathrm{s}}-N$ correlation presented by Skempton and Petley (1970) for peat and organic clay materials is not sufficiently precise for biosolid and sewage sludge materials. This is explained by the inherent differences in the nature (origin) of the organic fractions and in their mineralogical and organic compositions (O'Kelly, 2018a).

Note that the value of the void ratio (e) and other related parameters for biosolid and sewage sludge materials can be calculated from their measured water content and $N$ values - that is, for $S_{\mathrm{r}}=1.0$ and $e=w \times \rho_{\mathrm{s}}$, with the associated $\rho_{\mathrm{s}}$ value estimated using the presented correlation with the $N$ value.

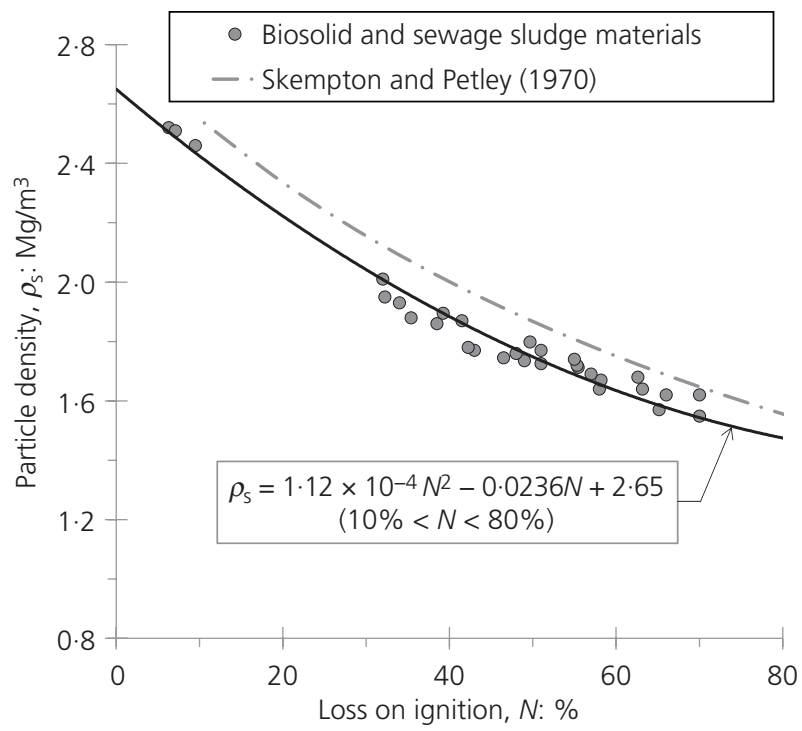

Figure 3. Correlation between particle density of solids and loss on ignition for biosolid and sewage sludge materials (adapted from O'Kelly (2018b)). Note that the $N$ value is determined for a specimen oven-drying temperature range of $110 \pm 5^{\circ} \mathrm{C}$ or $105-110^{\circ} \mathrm{C}$ and an ignition temperature of $440 \pm 25^{\circ} \mathrm{C}$

\section{pH determination}

For $\mathrm{pH}$ testing, the $\mathrm{pH}$ values of wet biosolid and sewage sludge specimens are typically measured both in deionised water and in calcium chloride solution using a $\mathrm{pH}$ meter that is regularly calibrated (O'Kelly et al., 2018a).

\section{Compaction testing}

Compared with inorganic clayey soil, compacted biosolid and sewage sludge materials have significantly greater $w_{\text {opt }}$ and air-void content values and significantly lower $\gamma_{\mathrm{d} \max }$ values (Arulrajah et al., 2011; O'Kelly, 2005b, 2006a). Compaction testing that starts with material prepared at $w>w_{\mathrm{opt}}$ and proceeds to $w<w_{\mathrm{opt}}$ (i.e. the water content value of the test material is successively reduced during the course of the compaction testing) produces marginally higher compacted bulk and dry unit weight values for these materials compared to the standard procedure (e.g. see BSI (1990d)) of starting the testing from the dry side, and proceeding to the wet side, of the $w_{\text {opt }}$ value (O'Kelly, 2016a).

For instance, Figure 4 compares these 'wet-to-dry' and 'dry-towet' testing approaches for standard Proctor compaction of the same sewage sludge material $(N=70 \%)$. This difference in compaction behaviour can be explained by the difficulty of achieving uniform rewetting of the dried biosolid (sewage sludge) peds (O'Kelly, 2016a). As such, the author recommends that compaction practice for these materials require the compaction testing to proceed from the wet side to the dry side of the $w_{\mathrm{opt}}$

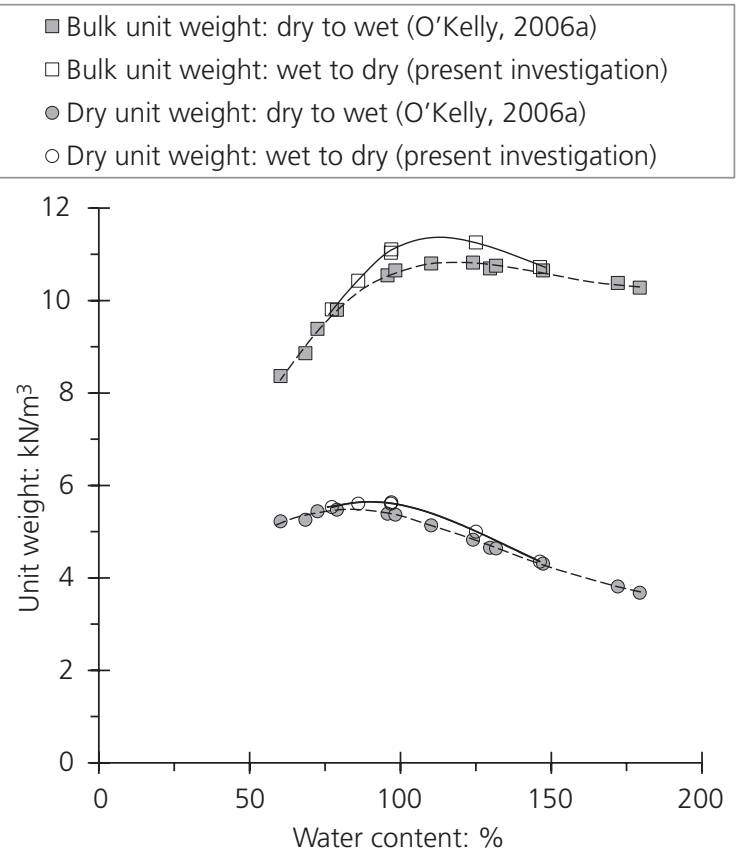

Figure 4. Standard Proctor compaction comparing wet-to-dry and dry-to-wet testing approaches for the same sewage sludge material $(N=70 \%)$ 
value. The same explanation and recommendation were reported by Wang et al. (1992) for compaction testing of water treatment residue (WTR) materials.

Further, when compacted at water contents significantly below the plastic limit value, the (semi-)solid peds of the biosolid, sewage sludge and WTR test specimens can crush under the impact of the compaction hammer, thereby significantly increasing the dry unit weight values achieved - that is, the compacted dry unit weight values produced for the solid and semi-solid states can be greater than the $\gamma_{\mathrm{d}} \max$ values obtained for the $w_{\text {opt }}$ values of these materials. In other words, when the compaction testing covers the very wide range of water contents encompassing the dry to wet material conditions, the shapes of the experimental dry unit weight against water content curves obtained for these materials may not exhibit the characteristic one-hump curve expected for inorganic clayey soil, as demonstrated for two alum WTR materials presented by Wang et al. (1992).

\section{Compression, consolidation and permeability testing}

\section{Testing apparatus and precautions}

Consolidometer, oedometer and hydraulic consolidation apparatuses allow investigations of the one-dimensional (1D) soil compression and consolidation properties. Flexible-wall permeameter and falling-head permeameter apparatuses, as well as hydraulic conductivity testing performed at the end of the load stages in oedometer or consolidometer tests, allow direct measurement of the permeability coefficient $(k)$ value.

Because of the corrosive nature of the biosolid and sewage sludge materials and the generally long duration of these tests, special precautions should be taken to avoid damage of the test apparatuses and their instrumentation. Specifically, components in contact with the test specimens should ideally be manufactured from either stainless steel (grade 316, or equivalent) or plastic material. Otherwise, apart from porous media which allow specimen drainage to occur, these components should be smeared with a thin film of grease as a preventative measure before setting up the test specimen and then thoroughly cleaned after completing the testing. Saturation with oil of the hydraulic lines to the pressure transducers protects both of these apparatus components from the corrosive effect of the leachate.

The porous media (discs) placed in contact with the specimen drainage boundaries must have the appropriate hydraulic characteristics, particularly for the testing of biosolid and sewage sludge materials. Partial or complete clogging of fine drainage discs can occur on account of bioclogging action and the entry of fine soil particles and biogenic gas bubbles which become trapped and occlude the pore throats of the drainage media. The resulting substantial reduction in the hydraulic conductivity of the drainage media has a knock-on effect in that the coefficient of consolidation $\left(c_{\mathrm{v}}\right)$ and $k$ values deduced from analyses of the experimental data are significantly lower compared to those of the test specimen/material (O'Kelly, 2016b).

For consolidation testing, the filtering action of finer drainage discs on the leachate can also produce a significant progressive increase in the viscosity of the pore liquid remaining within the test specimen (Kayser, 2012). Hence, in addition to the significant reduction in the $k$ value arising from the compression of the soil skeleton, a significant $k$ value reduction can also occur when testing biosolid and sewage sludge materials on account of the progressive increase in viscosity of the pore liquid caused by the filtering action of inappropriately used finer drainage discs. The latter effect is an artefact of the test condition and is not representative of the test material.

To mitigate against these unwanted effects, clean drainage discs with high water-permeability coefficient values (typically $\geq 10^{-5} \mathrm{~m} / \mathrm{s}$ ) must be used in laboratory apparatuses for performing consolidation and permeability tests (O'Kelly, 2016b). The removal of fine soil particles from the pores of the drainage discs can be aided by immersing them in an ultrasonic water bath. It is also recommended that their actual water-permeability coefficient values are verified experimentally, both before and after performing consolidation and permeability testing, thereby giving a direct measurement of any permeability reduction for the drainage discs which occurred over the course of the testing. Filter paper must not be placed between the specimen drainage boundaries and the drainage discs (O'Kelly, 2016b).

\section{Oedometer and consolidometer testing}

Multiple-increment oedometer testing of biosolid and sewage sludge materials requires that the initial heights of slurry and compacted test-specimens set up for the double-drainage condition should be approximately 30 and $19 \mathrm{~mm}$, respectively, with each load stage ideally of $48 \mathrm{~h}$ duration (O'Kelly, 2005a, 2006a, 2008a). These dimensions not only provide an effective drainage length that is necessarily short in order to allow excess biogas generated internally to escape from the test specimen, but also provide adequate initial specimen height considering the very large axial strains that occur with increasing effective stress (O'Kelly, 2005a, 2006a, 2008a). For greater initial specimen heights, experience has shown that slurry and very soft test specimens generally have not uniformly consolidated at the end of the longer stage durations required (O'Kelly, 1994). In other words, consolidation of the specimen core is significantly inhibited by the almost fully consolidated material (with significantly lower permeability coefficient values) located next to the specimen drainage discs (O'Kelly, 1994). Further, evolving biogas trapped within the core of test specimens that are too long causes an increase in their pore gas pressure and, hence, a reduction in the effective vertical pressure, such that these test specimens can never consolidate fully under the applied vertical stress (O'Kelly, 2005a, 2006a, 2008a, 2013b). For the same reasons, $38 \mathrm{~mm}$ dia. $\times 76 \mathrm{~mm}$ high specimens set up for the oneway vertical (i.e. the pore fluid pressure response is measured at 
one end of the test specimens) combined with radial drainage condition are recommended for triaxial consolidation testing of these materials. The same recommendation applies for triaxial effective-stress strength testing, which is discussed later in the paper.

O'Kelly (2008a) describes an oedometer set-up for testing of standard-diameter specimens, initially $14.8 \mathrm{~mm}$ high, but allowing vertical upward drainage only, with the pore fluid pressure response continuously measured at the bottom (closed end) of the specimen through a high air-entry-value (AEV) porous disc (fitted in the base of the consolidation cup) and the oil-saturated hydraulic line to the pressure transducer. As well as measuring the specimen axial strain $\left(\varepsilon_{\mathrm{a}}\right)$ response against elapsed time $(t)$, this oedometer set-up also allows the determination of the average degree of consolidation achieved throughout the course of each load stage (see O'Kelly (2008a)).

O'Kelly (2008b, 2009) describes a consolidometer apparatus (Figure 5) that incorporates a lubricated 'floating ring' confining cell to measure accurately the settlement response of $152 \mathrm{~mm}$ dia. slurry and soft soil test specimens (double-drainage condition) for

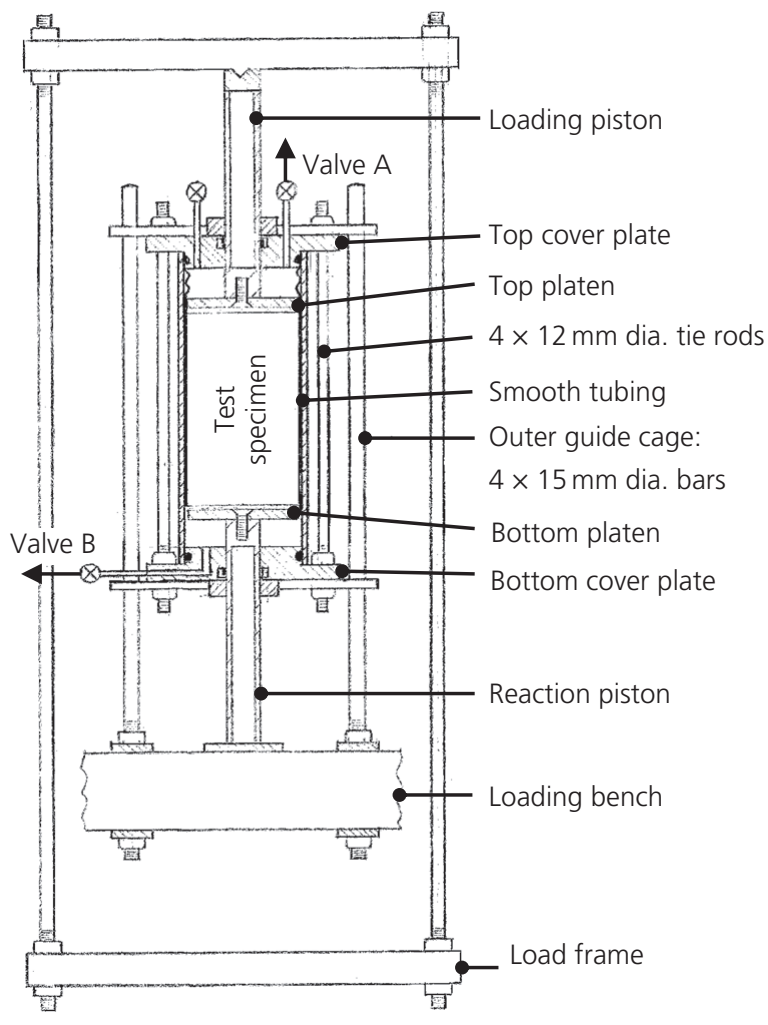

Figure 5. Schematic design of consolidometer apparatus for testing $152 \mathrm{~mm}$ dia. slurry and soft soil test specimens (adapted from O'Kelly (2008b)). With permission from the American Society of Civil Engineers. Note: the valves $A$ and $B$ remain fully opened during the consolidation tests (i.e. double-drainage condition) the applied vertical stress range of $0.5-40 \mathrm{kPa}$. Referring to Figure 5, the confining cell comprises a smooth tubing that is sealed at both ends by cover plates, which are bolted together by four $12 \mathrm{~mm}$ dia. tie rods. Hollow loading and reaction pistons are securely fastened to the top and bottom platens, respectively, which comfortably fit inside the confining cell and contact against the ends of the test specimen. The vertical movement of the floating-ring cell is guided by an outer cage comprising four $15 \mathrm{~mm}$ dia. vertical bars, which are bolted to the loading bench. Further details, including setting up of the test specimen and proving test results, are presented by O'Kelly (2008b, 2009).

\section{Analysing the experimental $\varepsilon_{a}-t$ data}

There are issues in applying 1D consolidation analyses and curvefitting techniques developed for inorganic fine-grained soil to biosolids, sewage sludge and other highly organic soils since these materials do not satisfy several essential assumptions of the underlying theory (O'Kelly, 2016b; O'Kelly and Zhang, 2013; Zhang and O'Kelly, 2014). For instance, Darcy's law is not valid for biosolid and sewage sludge materials since their pore fluid phase has a gel-like nature (Klein and Sarsby, 2000; O'Kelly, 2008a, 2016b; Sarsby, 2005) and, as an artefact of the test conditions, the viscosity of the pore liquid increases during the course of the consolidation test on account of the filtering action of the drainage discs (Kayser, 2012; O'Kelly, 2016a).

Consequently, the $\varepsilon_{\mathrm{a}}-t$ curves obtained for biosolid and sewage sludge materials from oedometer and consolidometer testing generally do not resemble the characteristic shapes given by the 1D consolidation theory for inorganic fine-grained soil (O'Kelly, 2005a, 2006a, 2008a, 2016a, 2016b). This makes the data interpretation using standard curve-fitting techniques difficult and sometimes not possible. For instance, the end of the primary consolidation phase (i.e. transition to the secondary compression (creep) phase) is often not readily discernible using standard curve fitting for biosolid and sewage sludge materials.

Rather than the characteristic ' $S$ '-shaped curve given by the theory, the experimental $\varepsilon_{\mathrm{a}}-\log t$ curves for these materials are distinctly different and are usually shaped concave downwards, such that their points of inflection are generally not evident (see Figure 6(a)).

Further, the secondary compression component often dominates over the primary consolidation component for these materials, particularly for higher effective vertical stress levels, such that the primary consolidation response is often masked by the secondary compression response. Consequently, the experimental $\varepsilon_{\mathrm{a}}-t^{1 / 2}$ curves obtained for these materials often present as approximately straight lines rather than the characteristic concave-upward shaped curve given by the theory (see Figure 6(b)), in which case the time period corresponding to $90 \%$ of the consolidation strain $\left(t_{90}\right)$ value also cannot be determined by standard curve fitting (O'Kelly, 2005a, 2006a; O'Kelly et al., 2018a). The increasing dominance of the secondary compression component over the 


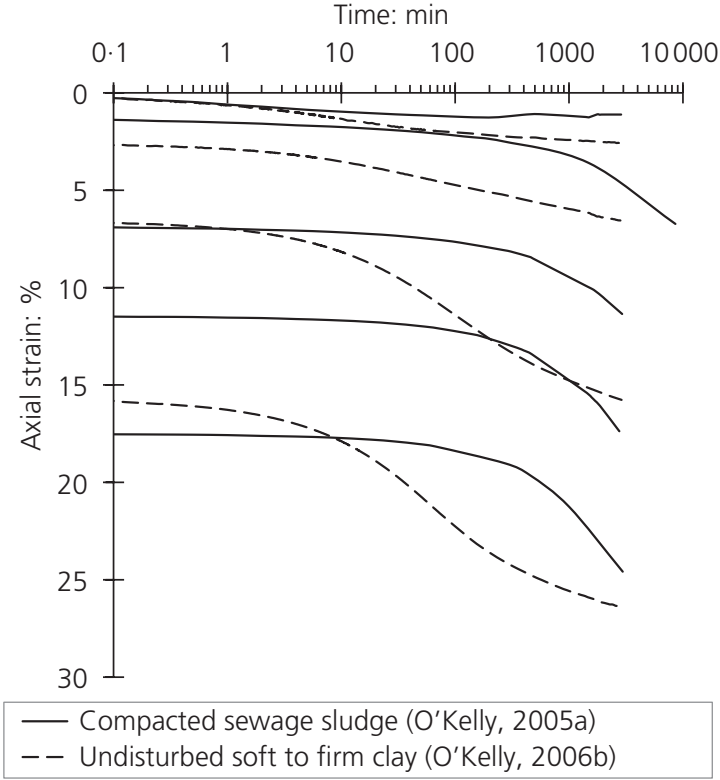

(a)

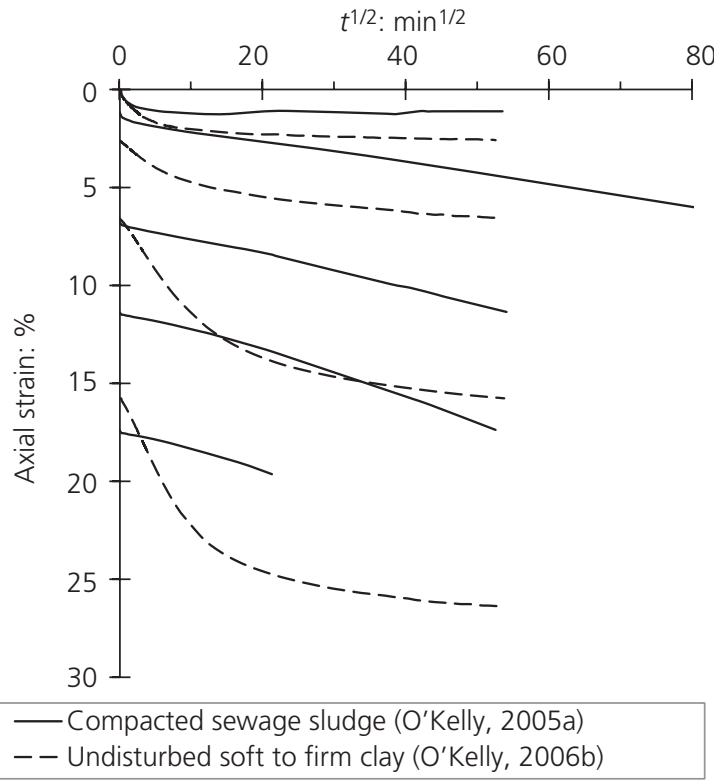

(b)

Figure 6. Typical consolidation curves for sewage sludge (biosolids) and inorganic clay from standard oedometer testing: (a) axial strain-log time plot; (b) axial strain-square root time plot. Note: $\sigma_{v}=25-400 \mathrm{kPa}$ for test specimen of sewage sludge $\left(w_{0}=130 \% ; w_{\mathrm{L}}=\right.$ $\left.315 \%, w_{\mathrm{P}}=55 \%, \rho_{\mathrm{s}}=1.55\left(\mathrm{O}^{\prime} \mathrm{Kelly}, 2005 \mathrm{a}\right)\right) ; \sigma_{\mathrm{v}}=12.5-200 \mathrm{kPa}$ for clay test specimen $\left(w_{0}=123 \% ; w_{\mathrm{L}}=90 \%, w_{\mathrm{P}}=35 \%, \rho_{\mathrm{s}}=2.70\right.$ (O'Kelly, 2006b)); load increment ratio of unity employed

primary consolidation component after the first (or sometimes the second) load stage (O'Kelly, 2008a) can be partly attributed to the use of inappropriate specimen drainage discs which have the effect of progressively increasing the viscosity of the pore liquid due to their filtering action on the leachate (O'Kelly, 2016b).

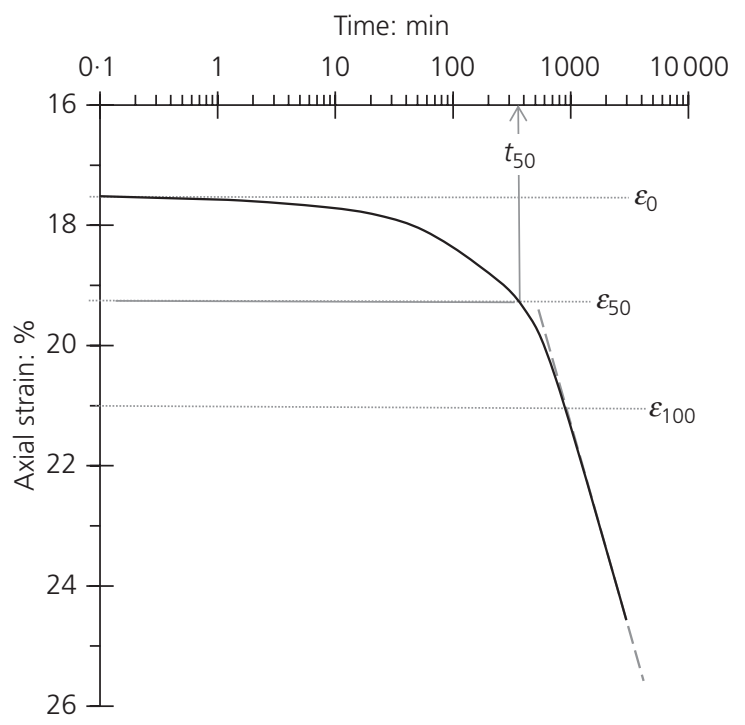

Figure 7. Modified curve-fitting approach for oedometer testing of sewage sludge (and biosolid) materials. Refer to Figure 6 caption for the test specimen properties
O’Kelly (2005a, 2006a, 2008b) and O'Kelly et al. (2018b) describe a modified curve-fitting approach for experimental $\varepsilon_{\mathrm{a}}-t$ data obtained for biosolid and sewage sludge materials (see also Figure 7), allowing the determination of their $c_{\mathrm{v}}$ values for a given load step based on the time period corresponding to $50 \%$ of the consolidation strain (i.e. $t_{50}$ value). Since some immediate strain can occur on load application, the initial step of the analyses involves the determination from the $\varepsilon_{\mathrm{a}}-t^{1 / 2}$ plot of the specimen strain $\varepsilon_{0}$ (i.e. corresponding to the start of the primary consolidation phase) for each load stage. After the first couple of load stages, however, the value of the immediate strain component for oedometer testing of these materials is usually negligible.

According to the standard $\varepsilon_{\mathrm{a}}-\log t$ curve-fitting technique, the secondary compression component of the specimen strain response appears as a straight line. Hence, in interpreting the experimental data for the biosolid and sewage sludge materials, the modified approach assumes that the end of the primary consolidation phase occurs for the specimen strain corresponding to the initial data point on the linear final portion of the experimental $\varepsilon_{\mathrm{a}}-\log t$ curve (O'Kelly, 2005a, 2006a, 2008b). Consequently, the $t_{50}$ value can be deduced as corresponding to half of the delineated primary consolidation strain component from the $\varepsilon_{\mathrm{a}}-\log t$ experimental curve (Figure 7). This approach is validated experimentally using the oedometer test results for sewage sludge materials $(N=55$ and $70 \%$ ) presented by O'Kelly (2008a), with the $t_{50}$ values deduced from the reported $\varepsilon_{\mathrm{a}}$ and $U$ against $\log t$ plots (where $U$ is the average degree of consolidation 
computed from the measured pore fluid pressure) in very good agreement.

For the first and possibly second load stages of the oedometer test, it is often possible also to determine the specimen strain corresponding to the $t_{90}$ value for slurry and very soft test specimens of biosolid and sewage sludge materials using the standard $\varepsilon_{\mathrm{a}}-t^{1 / 2}$ curve-fitting method. The deduced $t_{50}$ and $t_{90}$ values and their corresponding specimen strain values are then used to calculate the $c_{\mathrm{v}}$ values for each load step in the usual manner (e.g. see BSI (1990c)). The $t_{50}$ approach described has the advantage that it generally can be applied for all of the load stages and it also provides more definitive interpretation of the experimental curves than the $t_{90}$ approach, although when both approaches can be applied simultaneously, they are found to produce good overall agreement (O'Kelly et al., 2018a).

Note that inundation of compacted biosolid and sewage sludge specimens with water results in significant swelling occurring during the latter part of the initial load stage(s) (i.e. at low confinement stress levels) for oedometer testing on account of their compaction induced overconsolidated state (O'Kelly, 2004a, 2016a; O'Kelly et al., 2018a).

\section{Permeability measurement}

Permeability determinations using the flexible-wall permeameter apparatus, or from hydraulic conductivity tests performed at the end of the load stages in oedometer or consolidometer testing, are rarely undertaken on biosolid and sewage sludge materials on account of their extremely low $k$ values and, hence, the excessively long duration of such testing (O'Kelly, 2016b). For instance, O'Kelly et al. (2018a) describe constant-gradient permeability testing performed over a $2 \cdot 5$-month period on a $50.8 \mathrm{~mm}$ dia. $\times 50.8 \mathrm{~mm}$ high saturated compacted biosolid specimen, with very small final flow volumes of only approximately $10 \%$ of the pore void volume measured for an applied cell pressure $\left(\sigma_{\mathrm{c}}\right)$ value of $620 \mathrm{kPa}$, with the inlet and outlet pressures set at 559 and $531 \mathrm{kPa}$, respectively.

Hence, the $k$ values of these materials are invariably calculated from the oedometer coefficient of volume compressibility $\left(m_{\mathrm{v}}\right)$ and $c_{\mathrm{v}}$ values determined for the load stage under consideration that is, the permeability coefficient value is given as

2. $k=m_{\mathrm{v}} c_{\mathrm{v}} \times 3 \cdot 1 \times 10^{-10}(\mathrm{~m} / \mathrm{s})$

where $m_{\mathrm{v}}$ and $c_{\mathrm{v}}$ are expressed in units of $\mathrm{m}^{2} / \mathrm{MN}$ and $\mathrm{m}^{2} /$ year, respectively.

Although biodegradation induced (tertiary compression) settlement is generally not significant for oedometer testing of standard-sized compacted specimens of these materials at an ambient laboratory temperature of $20^{\circ} \mathrm{C}$ (O'Kelly et al., 2018a), the significantly higher temperatures anticipated within the body

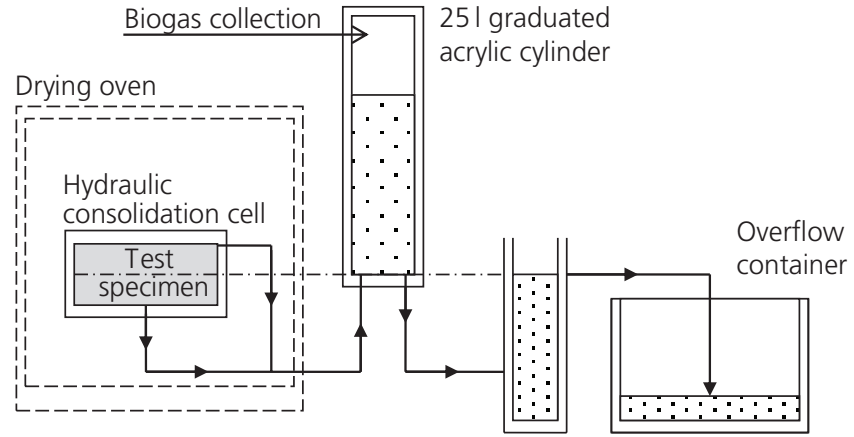

Figure 8. Experimental set-up for investigating anaerobic biodegradation of biosolid and sewage sludge materials at controlled elevated temperatures (after O'Kelly (2005a))

of landfilled (monofilled) deposits are likely to cause appreciable biodegradation in situ, with copious amounts of biogas generated. Disfani et al. (2013) presented an analytical method (that requires knowledge of the water content, $\mathrm{pH}$ value, biodegradable fraction, temperature and biodegradation rate) for predicting the biodegradation-induced settlement of biosolid deposits.

Using the experimental laboratory set-up shown in Figure 8, the rates and temperature dependencies of biodegradation and gas production can be investigated for biosolid and sewage sludge materials under various controlled drainage conditions, as well as the resulting increase in the pore fluid pressure over time. Further, using this set-up, samples contained in the large hydraulic consolidation cell can be biodegraded at accelerated rates by maintaining the oven temperature at a suitable elevated value, such that specimens with significantly different levels of decomposition can be prepared and subsequently tested to investigate the long-term effects of biodegradation on their geotechnical properties.

\section{Shear strength testing}

The principal approaches used for the determination of the shear strength of dewatered biosolid and sewage sludge materials are the fall cone (FC), vane shear (VS), unconfined compression, triaxial compression (TC) and direct shear (DS; i.e. shearbox) methods (O'Kelly, 2016a, 2016d).

The FC and VS approaches are suited for testing of slurry to softconsistency materials, allowing rapid assessment of their undrained strengths using portable devices, which is often required in practice. For instance, when dewatered material for landfilling has been transported in bulk to reach the landfill gate, the landfill operator needs to confirm that the material meets minimum strength requirements before accepting it for disposal on-site. Due consideration must be given, however, to the distinct geomechanical properties and behaviour of these materials (e.g. their significantly higher strain rate dependency of strength) compared to inorganic soils. In practical terms, the strength results 
obtained using the FC and VS approaches must be validated (calibrated) accordingly, as described in the following. These strength approaches do not provide a means of applying a confinement pressure to the test specimen and, hence, cannot simulate the in situ overburden stress conditions.

The TC approach allows full control of the specimen's confinement pressure and its drainage condition throughout the course of the testing and is ideally suited for soft- and firmerconsistency materials. Hence, this approach can be used to obtain pertinent strength measurements for different landfill scenarios, although it requires more sophisticated laboratory-based equipment and the testing is also more time consuming.

The mobilised strength value is dependent on many factors, including the soil's PSD, composition and mineralogy (in particular those of its fine fraction), the test specimen's size and its physical state (i.e. levels of compaction and saturation), its stress history and the applied confinement pressure, specimen boundary and drainage conditions and the shearing rate and mode adopted in performing the testing. With large shear strains required to mobilise the peak shear resistance of plastic biosolids and sewage sludge (O'Kelly, 2013a, 2013b, 2016a), the terminal strain values defined by limitations of the TC and DS apparatuses may not be sufficient to mobilise fully the strength of test specimens of these materials. The relationship between the water content and the remoulded undrained shear strength of biosolid material, as determined using the FC, VS and TC apparatuses, was investigated by O'Kelly (2013a, 2013b).

The biodegradation rates for slurry and very soft biosolids and in particular for sewage sludge are such that these materials occur in an unsaturated state, with the $S_{\mathrm{r}}$ value progressively reducing during the course of longer duration TC tests on account of the steady rate of accumulation of biogas generated internally (O'Kelly, 2005a, 2006a, 2008a, 2013b, 2018a). For this reason, before preparing very soft specimens of sewage sludge for consolidated undrained (CU) TC testing, O'Kelly (2005a, 2006a) pasteurised the test material by its heat treatment in the slurry state at $80^{\circ} \mathrm{C}$ over a $5 \mathrm{~h}$ period by using the apparatus shown in Figure 8. It was contended that the measured back-pressure saturated triaxial $c^{\prime}$ and $\phi^{\prime}$ values were appropriate for the analysis of the monofilled sludge at that particular state of degradation, provided effective biogas control and leachate drainage systems are in place (O’Kelly, 2016a).

Based on the experimental results presented by O'Kelly et al. (2018a), it is the author's opinion that the effect of ongoing biogas generation is not as significant for routine CU TC, DS and direct simple shear (DSS) testing of compacted biosolid and sewage sludge materials. This is consistent with the observation of O'Kelly et al. (2018a) that tertiary compression (i.e. specimen deformation arising from loss of susceptible organic matter due to biodegradation) was not discernible from analysis of the $\varepsilon_{\mathrm{a}}-\log t$ curve obtained for a $42 \mathrm{~d}$ oedometer load stage performed on saturated compacted biosolid material $(N=63 \%)$ tested at an ambient laboratory temperature of $20^{\circ} \mathrm{C}$.

The same recommendations presented in the section headed 'Testing apparatus and precautions' for laboratory consolidation and permeability testing of biosolid and sewage sludge materials apply to the selection and verification of appropriate specimen drainage discs for use in strength testing that involves backpressure saturation and consolidation stages and also for drained compression - that is, porous discs with relatively low AEVs are required at the specimen drainage boundaries (O'Kelly, 2016b). Saturated fine porous discs with high AEVs are required to allow measurement of the pore liquid pressure response using pressure transducers (O’Kelly, 2016b).

\section{FC method}

The FC method is quick, repeatable and straightforward in its execution. Further, this approach has been standardised and adopted in many countries as the preferred method for the determination of the liquid limit - for example, using the $30^{\circ}-80 \mathrm{~g}$ fall cone apparatus (BSI, 1990a). It is also used to determine the undrained strength of intact and remoulded finegrained soils for different water contents within their plastic ranges (e.g. using the $30^{\circ}-100 \mathrm{~g}$ or $30^{\circ}-400 \mathrm{~g}$ fall cones) (Geonor, 2015) and the soil sensitivity (i.e. the ratio of the undisturbed to remoulded strengths) (O'Kelly et al., 2018b). For all of these applications, the stationary contacting cone is allowed to fall under its own weight and penetrate into the soil test specimen, with the measured penetration depth $(h)$ related to the mobilised 'static' undrained shear strength $\left(s_{\mathrm{u}}\right)$, according to the equation

3. $s_{\mathrm{u}}=\frac{K W}{h^{2}}$

where $W$ is the cone weight and $K$ is the cone factor.

Coarse particles and fibres present in the test specimens may significantly reduce the cone's penetration depth, thereby causing an overprediction of the actual strength value and (or) producing erratic results for repeat FC tests. Hence, it is recommended that if significant amounts of these components are present in the sampled biosolid and sewage sludge materials, they should be removed by wet sieving to pass the $425 \mu \mathrm{m}$ test sieve before performing the FC tests (O'Kelly, 2016a, 2018c). Alternatively, the sieving process for sampled materials of slurry or very soft consistency can involve rubbing them under light hand pressure through the delineating sieve, as described by O'Kelly (2015a).

For strength testing of remoulded inorganic fine-grained soils using the $30^{\circ}$ fall cone, the appropriate value of $K$ for use in Equation 3 is 0.85 (Wood, 1985). Organic soils typically have significantly greater strain rate dependence of strength compared to inorganic soils, which have a rate dependence parameter $(\mu)$ 
value of $10 \pm 5 \%$ (Kulhawy and Mayne, 1990). The $\mu$ value is dependent on the soil type and indicates the percentage increase in its mobilised undrained strength for a tenfold increase in the shear strain rate. For instance, finely shredded Clara Bog peat $(w=610 \% ; N=98.8 \%)$ and alum WTR $(w=222 \% ; N=57 \%)$ materials have reported $\mu$ values of 28 and $20 \%$, respectively (O’Kelly, 2016a, 2018c).

To date, only two studies have reported on the strain rate dependence of saturated biosolid materials, with no such information available for sewage sludge material. Specifically, $\mu$ values of 38\% ( $w=355 \%, N=66-70 \%$ (O'Kelly, 2016a)) and $\sim 21 \%(w \approx 109 \%, N=63 \%$ (O'Kelly et al., 2018a)) were deduced from unconsolidated undrained (UU) TC data, with a $\mu$ value of $41 \%$ also deduced for the latter material from DSS data (O'Kelly et al., 2018a). Based on these very limited data, a $\mu$ value of approximately $30 \%$ is tentatively suggested as representative for biosolid and sewage sludge materials.

For FC testing, the mean strain rates are very high, typically on the order of $10^{6} \% / \mathrm{h}$ (Koumoto and Houlsby, 2001). As explained in the papers by O'Kelly (2018c) and O'Kelly et al. (2018b), the appropriate value of $K$ for use in Equation 3 (and, hence, the calculated undrained strength value) decreases with increasing strain rate dependence. The practical significance for FC testing of biosolid and sewage sludge materials is demonstrated with reference to a particular example considering the $30^{\circ}-400 \mathrm{~g}$ fall cone. For $h=8.8 \mathrm{~mm}$, employing a $K$ value of $0.85(\mu=10 \%)$ in the calculations would produce an $s_{\mathrm{u}}$ value of $50 \mathrm{kPa}$, whereas the mobilised strength value for these higher-strain-ratedependency materials (i.e. $\mu \approx 30 \%$ ) would be significantly smaller, at approximately $29 \mathrm{kPa}$.

Hence, to achieve accurate strength interpretations for these materials, it is important to firstly correlate the FC data (i.e. achieve a one-to-one correspondence) with some static $s_{u}$ data (e.g. obtained from VS, unconfined compression or UU TC tests) in order to establish an appropriate experimental $K$ value for use in Equation 3 (O'Kelly, 2016a). Alternatively, as explained in the papers by O'Kelly (2018c) and O'Kelly et al. (2018b), for a given cone apex angle and with knowledge of the cone surface roughness properties and also the $\mu$ value of the test material, an appropriate $K$ value can be calculated from theory and making use of the numerical analysis results presented by Hazell (2008). To overcome the uncertainties regarding the test material's strain rate dependence, a different approach is to use pseudo-static cones that are mechanically pushed into the soil test specimen to measure the static undrained strength directly (e.g. see Stone and Kyambadde (2007))

For biosolid and sewage sludge materials of slurry consistency, FC strength interpretations are further complicated on account of the additional complexity introduced by the effect of the viscous gel-like pore fluid (Klein and Sarsby, 2000; O'Kelly, 2013a, 2018c). Methods of analyses are presented by O'Kelly (2013a) for estimating the significant pore fluid contribution to the mobilised strength for these materials in the slurry state.

\section{Laboratory VS}

The laboratory vane apparatus has a fixed frame-and-head assembly that rotates a cruciform vane (e.g. $12.7 \times 12.7 \mathrm{~mm}$ or $25 \times 25 \mathrm{~mm}$ ) at approximately $9 \%$ min to cause shear failure of the soil test material to occur over a cylindrical surface. If present in the test material, coarse fibres will affect smaller vanes to a greater extent, potentially resulting in an overprediction of the actual strength value (O'Kelly, 2013a, 2016a). Hence, larger vane sizes are recommended, particularly for testing of low-strength materials.

\section{Triaxial compression}

Biosolid and sewage sludge deposits invariably exist in a partially saturated state, with larger $s_{\mathrm{u}}$ values mobilised for greater overburden pressure - that is, these materials do not behave as $\phi_{\mathrm{u}}=0$ during shearing for different confinement pressures, where $\phi_{\mathrm{u}}$ is the undrained angle of shearing resistance (Kayser et al., 2011; O'Kelly, 2013a, 2013b, 2016a). Hence in determining the undrained shear strength, the $\sigma_{\mathrm{c}}$ value applied in performing UU TC testing should simulate anticipated typical overburden stress ranges. Unconfined compression testing can also be employed and provides a lower-bound strength value for a given shearing rate (O'Kelly, 2013b).

The test specimens, typically 38,50 or $75 \mathrm{~mm}$ dia., are usually prepared by static or dynamic compaction of the materials into specimen moulds or by carving them from samples compacted into standard compaction moulds. The materials are generally compacted at specified water contents by applying a specified compaction effort or to achieve specified dry unit weights. An alternative approach is described in the papers by O'Kelly (2005a, 2006a), whereby saturated triaxial test specimens are prepared from the compressed cake materials obtained by consolidation from a slurry condition using a large hydraulic consolidation cell device. Saturated biodegraded and (or) pasteurised triaxial test specimens can also be prepared using this approach and the experimental laboratory set-up described in the section headed 'Permeability measurement' and also shown in Figure 8.

To date, CU TC testing is the most frequently used approach for the determination of the $c^{\prime}$ and $\phi^{\prime}$ values of the various biosolid and sewage sludge materials investigated. CU TC tests involve saturation, consolidation and compression (shearing) stages. In the author's experience, it is not practical to achieve full saturation of compacted biosolid and sewage sludge test specimens by increasing the cell pressure only (i.e. at constant water content). For example, a $38 \mathrm{~mm}$ dia. sewage sludge test specimen $(N=70 \%)$ prepared by standard Proctor compaction at $130 \%$ water content required a $34 \mathrm{~d}$ period to achieve a pore pressure coefficient $B$ value of approximately 0.93 for an applied cell pressure of $300 \mathrm{kPa}$ (O'Kelly, 1994). An adequate level of saturation (i.e. $B$ value $\geq 0.95$ ) can be achieved for the compacted 
materials by applying very high back-pressures. For example, back-pressure values ranging typically from 895 to $1040 \mathrm{kPa}$ were necessary for CU TC testing of biosolid material $(N=63 \%)$ compacted at approximately $100 \%$ water content (O'Kelly et al., 2018a).

The biosolid and sewage sludge test specimens must be set up for one-way vertical combined with radial drainage (O'Kelly, 2006a; O'Kelly et al., 2018a) - that is, allowing measurement of the pore liquid pressure response through a high $\mathrm{AEV}$ disc in contact with its closed end (O'Kelly, 2016b). Otherwise, the durations of the CU TC tests are excessively long on account of the extremely low $k$ values of these materials. For instance, even with radial boundary and one-end drainage provided, the required duration of the consolidation stage for the 36 and $51 \mathrm{~mm}$ dia. compacted biosolid test specimens investigated by O'Kelly et al. (2018a) ranged between 1 and $8.25 \mathrm{~d}$ to achieve targeted effective cell pressures of $75-300 \mathrm{kPa}$, with the overall duration for completion of these CU TC tests ranging between 1.7 and $10 \cdot 6 \mathrm{~d}$. For the same reason, consolidated drained (CD) TC testing is not recommended for these materials.

The compression stage of the $\mathrm{UU}$ and $\mathrm{CU}$ triaxial tests must generally be continued to $\varepsilon_{\mathrm{a}}>20 \%$ for these materials in order to mobilise fully their peak deviatoric stress (O'Kelly, 2006a, 2013a), applying standard corrections for the restraining effects of the enclosing rubber membrane and any filter paper drains fitted to the side-surface of the test specimen. The triaxial undrained shear strength is determined as half of the corrected peak deviatoric stress value.

For CU TC tests performed at low effective confinement pressures, biosolid and sewage sludge specimens prepared by compaction at $w<w_{\text {opt }}$ can undergo significant swelling and, hence, absorb significant amounts of water during the triaxial saturation and 'consolidation' stages on account of their compaction-induced overconsolidated (OC) condition. Consequently, the water content value during the triaxial compression stage may be significantly greater than the initial water content value of the compacted test specimen (O'Kelly et al., 2018a). Under these circumstances, lower strength values can be mobilised compared to the same materials compacted at $w>w_{\text {opt }}$ (O'Kelly et al., 2018a).

\section{Determination of the effective-stress strength parameter values}

Normally consolidated (NC) effective angle of shearing resistance $\left(\phi_{\mathrm{NC}}^{\prime}\right)$ values ranging from 32 to $42^{\circ}$ (Arulrajah et al., 2011; Disfani et al., 2015; GLSEC, 2003; O'Kelly, 2005e, 2006a) have been deduced from CU TC testing for biosolid and sewage sludge materials. These angle of shearing resistance values, however, are considered unrealistically high for use in practice and should not be relied on in geotechnical design (O'Kelly, 2016a; O'Kelly et al., 2018a). DS and DSS testing seem to provide more realistic $\phi_{\mathrm{NC}}^{\prime}$ values for these materials. For instance, $\phi_{\mathrm{NC}}^{\prime}=10-15^{\circ}$ was deduced from CD DS testing of sewage sludge $(N=32 \cdot 3-51 \cdot 0 \%)$
(Zhan et al., 2014) and $\phi_{\mathrm{NC}}^{\prime}=15 \cdot 5^{\circ}$ was deduced from CU DSS testing of water-inundated compacted biosolid material $(N=63 \%)$ (O'Kelly et al., 2018a). Similar general conclusions have been reported for (fibrous) peat materials - that is, compared with TC, the DS and DSS approaches provide conservative $\phi^{\prime}$ values that are appropriate for analyses of translational (sliding) failure mechanisms (O'Kelly, 2015b, 2017; O'Kelly and Orr, 2014).

However, with careful consideration of the stress history, it appears that consistent and realistic values of $\phi_{\mathrm{NC}}^{\prime}$ can be measured for biosolids and sewage sludge using these different approaches. For example, O'Kelly et al. (2018a) determined $\phi_{\mathrm{NC}}^{\prime}$ values of $15 \cdot 1,16 \cdot 3$ and $15 \cdot 5^{\circ}$ (with $c^{\prime}=0 \mathrm{kPa}$ ) from CU TC, $\mathrm{CU}$ triaxial extension and CU DSS, respectively, for saturated compacted biosolid material $(N=63 \%)$ tested in the NC state. In other words, the effective confinement pressure and pre-shear vertical consolidation stress values at the start of the shearing stage in CU TC and CU DSS, respectively, must exceeded the material's apparent pre-consolidation stress value in order to allow measurement of these $\phi_{\mathrm{NC}}^{\prime}$ values (O'Kelly et al., 2018a).

With the mobilised shear resistance continuing to increase in value for increasing axial (shear) strain, it can be deduced whether the test specimens are in an $\mathrm{NC}$, marginally $\mathrm{OC}$, moderately OC or heavily OC state based on the observed shapes of the experimental excess pore fluid pressure against $\varepsilon_{\mathrm{a}}$ plots and also the values of the pore pressure coefficient $A$ at failure. Further details of these assessments are described for CU TC and CU DSS testing of biosolid material in O'Kelly et al. (2018a).

With an increasing level of overconsolidation, the $c^{\prime}$ and $\phi^{\prime}$ parameter values increase and decrease, respectively, such that saturated heavily OC biosolid material $(N=63 \%)$ investigated by O'Kelly et al. (2018a) had $c_{\mathrm{TC}}^{\prime}$ and $\phi_{\mathrm{TC}}^{\prime}$ values of $23 \mathrm{kPa}$ and $1.9^{\circ}$, respectively, and $c_{\mathrm{DSS}}^{\prime}$ and $\phi_{\mathrm{DSS}}^{\prime}$ values of $32 \mathrm{kPa}$ and $2 \cdot 5^{\circ}$, respectively. In other words, the saturated compacted biosolid material had isotropic $\phi^{\prime}$ properties for the NC state, but its effective-stress strength parameter values were cross-anisotropic for the OC state, with the strength anisotropy for the OC state predominantly arising from the compaction process (O'Kelly et al., 2018a).

\section{Discussion and conclusions}

Biosolid and sewage sludge materials are difficult, challenging and unconventional geomaterials. Nevertheless, as demonstrated in this paper, their geotechnical properties can be accurately assessed using laboratory testing provided that due care and attention are given to their distinctive behaviours, with some procedural modifications to the standard test methods, data analyses and interpretation necessary.

Due consideration must be given to their distinctive geomechanical properties and behaviour compared to those of inorganic soils. For instance, the $K$ value employed in FC undrained strength calculations must be calibrated for the biosolid and sewage sludge 
materials under investigation on account of their significantly greater strain-rate dependency of strength. Further, it is important to take the stress history (e.g. the compaction induced OC state of compacted materials) into account when designing strength testing programmes and in the interpretation of the experimental data for the determination of the effective-stress strength parameter values.

Given the health and safety risks associated with testing of these materials, as well as their corrosive nature for laboratory equipment and instrumentation, it is recommended that synthetic biosolid and sewage sludge materials are developed for performing basic and applied geotechnical laboratory investigations of these materials as well as interlaboratory trials for the validation of standards.

\section{REFERENCES}

Arulrajah A, Disfani MM, Suthagaran V and Imteaz M (2011) Select chemical and engineering properties of wastewater biosolids. Waste Management 31(12): 2522-2526, https://doi.org/10.1016/j.wasman. 2011.07.014

Arulrajah A, Disfani MM, Suthagaran V and Bo MW (2013) Laboratory evaluation of the geotechnical characteristics of wastewater biosolids in road embankments. Journal of Materials in Civil Engineering 25(11): 1682-1691, https://doi.org/10.1061/(ASCE)MT.1943-5533. 0000739 .

ASTM (2010) D 2216-10: Standard test methods for laboratory determination of water (moisture) content of soil and rock by mass. ASTM International, West Conshohocken, PA, USA.

ASTM (2014) D 2974-14: Standard test methods for moisture, ash, and organic matter of peat and other organic soils. ASTM International, West Conshohocken, PA, USA

BSI (1990a) BS 1377-2:1990: Methods of test for soils for civil engineering purposes (classification tests). BSI, London, UK.

BSI (1990b) BS 1377-3:1990: Methods of test for soils for civil engineering purposes (chemical and electro-chemical tests). BSI, London, UK.

BSI (1990c) BS 1377-6:1990: Methods of test for soils for civil engineering purposes (consolidation and permeability tests in hydraulic cells and with pore pressure measurement). BSI, London, UK.

BSI (1990d) BS 1377-4:1990: Methods of test for soils for civil engineering purposes (compaction-related tests). BSI, London, UK.

Chen P, Zhan L and Wilson W (2014) Experimental investigation on shear strength and permeability of a deeply dewatered sewage sludge for use in landfill covers. Environmental Earth Sciences 71(10): 4593-4602, https://doi.org/10.1007/s12665-013-2851-8.

Diliūnas J, Dundulis K, Gadeikis S, Jurevičius A and Kaminskas M (2010) Geotechnical and hydrochemical properties of sewage sludge. Bulletin of Engineering Geology and the Environment 69(4): 575-582, https://doi.org/10.1007/s10064-010-0279-x.

Disfani MM, Arulrajah A, Suthagaran V and Bo MW (2013) Long-term settlement prediction for wastewater biosolids in road embankments. Resources, Conservation and Recycling 77: 69-77, https://doi.org/10. 1016/j.resconrec.2013.05.009.

Disfani MM, Arulrajah A, Maghoolpilehrood F, Bo MW and Narsilio GA (2015) Geotechnical characteristics of stabilised aged biosolids. Environmental Geotechnics 2(5): 269-279, https://doi.org/10.1680/ envgeo.13.00054.

Geonor (2015) Data Sheet on GEONOR Fall Cone Apparatus. Geonor, Augusta, NJ, USA. See http://geonor.com/datasheets/Geonor_Fall_ Cone Apparatus.pdf (accessed 31/01/2018).

GLSEC (Great Lakes Soil \& Environmental Consultants) (2003) Geotechnical Characterization of Biosolids. Research and Development Department, Metropolitan Water Reclamation
District of Greater Chicago, Chicago, IL, USA, Report No. 03-8. See https:/www.mwrd.org/irj/go/km/docs/documents/MWRD/internet/ reports/Monitoring_and_Research/pdf/2003/03-08_Geotechnical_ Characterization_of_Biosolids.pdf (accessed 08/03/2018).

Hazell E (2008) Numerical and Experimental Studies of Shallow Cone Penetration in Clay. DPhil thesis, University of Oxford, Oxford, UK.

Hobbs NB (1986) Mire morphology and the properties and behaviour of some British and foreign peats. Quarterly Journal of Engineering Geology 19(1): 7-80, https://doi.org/10.1144/GSL.QJEG.1986.019.01. 02 .

Johnston PM and O'Kelly BC (2016) Importance of environmental geotechnics. Environmental Geotechnics 3(6): 356-358, https://doi. org/10.1680/envgeo.13.00123.

Kayser C (2012) The Geotechnical and Environmental Properties of Amended Biosolids. PhD thesis, University of Auckland, Auckland, New Zealand. See http://hdl.handle.net/2292/18902 (accessed 08/03/2018).

Kayser C, Larkin T and Singhal N (2011) Enhancement of the shear strength of wastewater residuals using industrial waste by-products. Journal of Environmental Engineering 137(11): 1002-1011, https://doi.org/10.1061/(ASCE)EE.1943-7870.0000426.

Kayser C, Larkin T and Singhal N (2015) Amendment of biosolids with waste materials and lime: effect on geoenvironmental properties and leachate production. Waste Management 46: 165-175, https://doi.org/ 10.1016/j.wasman.2015.08.024.

Klein A and Sarsby RW (2000) Problems in defining the geotechnical behaviour of wastewater sludges. In Geotechnics of High Water Content Materials (Edil TB and Fox PJ (eds)). ASTM, West Conshohocken, PA, USA, STP 1374, pp. 74-87.

Koumoto T and Houlsby GT (2001) Theory and practice of the fall cone test. Géotechnique 51(8): 701-712, https://doi.org/10.1680/geot.2001. 51.8.701.

Kulhawy FH and Mayne PW (1990) Manual on Estimating Soil Properties for Foundation Design. Electric Power Research Institute, Palo Alto, CA, USA, Report No. EL-6800. See https://www.epri.com/\#/pages/ product/EL-6800/ (accessed 08/03/2018).

Metcalf \& Eddy (2004) Wastewater Engineering: Treatment and Reuse, 4th edn. (revised by Tchobanoglous G, Burton FL and Stensel HD). McGraw-Hill, Singapore.

O'Kelly BC (1994) Mechanical Properties and Slope Stability of Dewatered Digested Sewage Sludge. MEngSc thesis, University College Dublin, Dublin, Ireland. See http://hdl.handle.net/2262/67065 (accessed 08/03/2018).

O'Kelly BC (2004a) Geotechnical aspects of sewage sludge monofills. Proceedings of the Institution of Civil Engineers - Municipal Engineer 157(3): 193-197, https://doi.org/10.1680/muen.2004.157.3. 193.

O'Kelly BC (2004b) Accurate determination of moisture content of organic soils using the oven drying method. Drying Technology 22(7): 1767-1776, https://doi.org/10.1081/DRT-200025642.

O'Kelly BC (2005a) Consolidation properties of a dewatered municipal sewage sludge. Canadian Geotechnical Journal 42(5): 1350-1358, https://doi.org/10.1139/t05-054.

O'Kelly BC (2005b) Sewage sludge to landfill: some pertinent engineering properties. Journal of the Air and Waste Management Association 55(6): 765-771, https://doi.org/10.1080/10473289.2005.10464670.

O'Kelly BC (2005c) New method to determine the true water content of organic soils. Geotechnical Testing Journal 28(4): 365-369, https:// doi.org/10.1520/GTJ11963.

O'Kelly BC (2005d) Method to compare water content values determined on the basis of different oven drying temperatures. Géotechnique 55(4): 329-332, https://doi.org/10.1680/geot.2005.55.4.329.

O'Kelly BC (2005e) Mechanical properties of dewatered sewage sludge. Waste Management 25(1): 47-52, https://doi.org/10.1016/j.wasman. 2004.08.003. 
O'Kelly BC (2006a) Geotechnical properties of municipal sewage sludge. Geotechnical and Geological Engineering 24(4): 833-850, https://doi.org/10.1007/s10706-005-6611-8.

O'Kelly BC (2006b) Compression and consolidation anisotropy of some soft soils. Geotechnical and Geological Engineering 24(6): 1715-1728, https://doi.org/10.1007/s10706-005-5760-0.

O'Kelly BC (2008a) Effect of biodegradation on the consolidation properties of a dewatered municipal sewage sludge. Waste Management 28(8): 1395-1405, https://doi.org/10.1016/j.wasman. 2007.08.004.

O'Kelly BC (2008b) Development of a large consolidometer-permeameter apparatus for testing soft soils. In GeoCongress 2008: Characterization, Monitoring, and Modeling of GeoSystems (Alshawabkeh AN, Reddy KR and Khire MV (eds)). American Society of Civil Engineers (ASCE), Reston, VA, USA, GSP 179, vol. 5, pp. 60-67.

O’Kelly BC (2009) Development of a large consolidometer apparatus for testing peat and other highly organic soils. SUO - Mires and Peat 60(1/2): 23-36.

O'Kelly BC (2013a) Undrained shear strength-water content relationship for sewage sludge. Proceedings of the Institution of Civil Engineers Geotechnical Engineering 166(6): 576-588, https://doi.org/10.1680/ geng.11.00016.

O'Kelly BC (2013b) Discussion of 'Enhancement of the shear strength of wastewater residuals using industrial waste by-products'. Journal of Environmental Engineering 139(2): 312-315, https://doi.org/10.1061/ (ASCE)EE.1943-7870.0000608

O'Kelly BC (2014) Drying temperature and water content-strength correlations. Environmental Geotechnics 1(2): 81-95, https://doi.org/ 10.1680/envgeo.13.00016

O'Kelly BC (2015a) Atterberg limits are not appropriate for peat. Geotechnical Research 2(3): 123-134, https://doi.org/10.1680/jgere. 15.00007 .

O'Kelly BC (2015b) Effective stress strength testing of peat. Environmental Geotechnics 2(1): 33-44, https://doi.org/10.1680/ envgeo.13.00112.

O'Kelly BC (2016a) Geotechnics of municipal sludges and residues for landfilling. Geotechnical Research 3(4): 148-179, https://doi.org/10. 1680/jgere.16.00013.

O'Kelly BC (2016b) Briefing: Laboratory permeability determinations for biosolids. Environmental Geotechnics 3(3): 132-139, https://doi.org/ 10.1680 /jenge. 15.00026 .

O'Kelly BC (2016c) Briefing: Atterberg limits and peat. Environmental Geotechnics 3(6): 359-363, https://doi.org/10.1680/envgeo.15.00003.

O'Kelly BC (2016d) Assessing the shear strength of municipal sludges and residues for landfill disposal. In Proceedings of the 3rd Symposium on Urban Mining and Circular Economy (SUM2016), Bergamo, Italy (Cossu R, Lavagnolo MC and Mudhoo A (eds)). Cisa, Padova, Italy, CD-ROM. See http://cisapublisher.com/about/ (accessed 28/03/2018)

O'Kelly BC (2017) Measurement, interpretation and recommended use of laboratory strength properties of fibrous peat. Geotechnical Research 4(3): 136-171, https://doi.org/10.1680/jgere.17.00006.

O'Kelly BC (2018a) Biodegradation of biosolids and specific gravity determination. Environmental Geotechnics, https://doi.org/10.1680/ jenge. 16.00014

O'Kelly BC (2018b) Corrigendum: Biodegradation of biosolids and specific gravity determination. Environmental Geotechnics 5(1): 63, https://doi.org/10.1680/jenge.2018.5.1.63.

O'Kelly BC (2018c) Fall-cone strength testing of municipal sludges and residues. Environmental Geotechnics 5(1): 18-30, https://doi.org//10. 1680 /jenge. 15.00080

O'Kelly BC and Orr TLL (2014) Briefing: Effective-stress strength of peat in triaxial compression. Proceedings of the Institution of Civil Engineers - Geotechnical Engineering 167(5): 417-420, https://doi. org/10.1680/geng.13.00143.
O'Kelly BC and Pichan SP (2013) Effects of decomposition on the compressibility of fibrous peat - a review. Geomechanics and Geoengineering 8(4): 286-296, https://doi.org/10.1080/17486025. 2013.804210 .

O'Kelly BC and Quille ME (2009) Compressibility and consolidation of water treatment residues. Proceedings of the Institution of Civil Engineers - Waste and Resource Management 162(2): 85-97, https://doi.org/10.1680/warm.2009.162.2.85.

O'Kelly BC and Sivakumar V (2014) Water content determinations for peat and other organic soils using the oven-drying method. Drying Technology 32(6): 631-643, https://doi.org/10.1080/07373937.2013. 849728.

O'Kelly BC and Zhang L (2013) Consolidated-drained triaxial compression testing of peat. Geotechnical Testing Journal 36(3): 310-321, https://doi.org/10.1520/GTJ20120053.

O'Kelly BC, Oettle NK and Ramos JA (2018a) Geotechnical properties of compacted biosolids for monofill design. Environmental Geotechnics, https://doi.org/10.1680/jenge.17.00107.

O'Kelly BC, Vardanega PJ and Haigh SK (2018b) Use of fall cones to determine Atterberg limits: a review. Géotechnique, https://doi.org/ 10.1680/jgeot.17.R.039.

Sarsby RW (2005) Geotechnical properties of sewage sludge. In Proceedings of the 16th International Conference on Soil Mechanics and Geotechnical Engineering (ICSMGE), Osaka, Japan (Organizing Committee of the 16th ICSMGE Conference (eds)) Millpress Science, Rotterdam, the Netherlands, vol. 4, pp. 2327-2329.

Skempton AW and Petley DJ (1970) Ignition loss and other properties of peats and clays from Avonmouth, King's Lynn and Cranberry Moss. Géotechnique 20(4): 343-356, https://doi.org/10.1680/geot.1970.20.4. 343.

Stone KJL and Kyambadde BS (2007) Determination of strength and index properties of fine-grained soils using a soil minipenetrometer. Geotechnical and Geoenvironmental Engineering 133(6): 667-673, https://doi.org/10.1061/(ASCE)1090-0241(2007)133:6(667).

Stone RJ, Ekwue El and Clarke RO (1998) Engineering properties of sewage sludge in Trinidad. Journal of Agricultural and Engineering Research 70(2): 221-230, https://doi.org/10.1006/jaer. 1998.0266.

USEPA (US Environmental Protection Agency) (2001) Method 1684: Total, Fixed, and Volatile Solids in Water, Solids, and Biosolids. USEPA, Washington, DC, USA, Report No. EPA-821-R-01-015.

Wang MC, Hull JQ, Jao M, Dempsey BA and Cornwell DA (1992) Engineering behavior of water treatment sludge. Journal of Environmental Engineering 118(6): 848-864, https://doi.org/10.1061/ (ASCE)0733-9372(1992)118:6(848).

Wood DM (1985) Some fall-cone tests. Géotechnique 35(1): 64-68, https://doi.org/10.1680/geot.1985.35.1.64.

Zhan TL, Zhan Z, Lin W, Luo X and Chen Y (2014) Field and laboratory investigation on geotechnical properties of sewage sludge disposed in a pit at Changan landfill, Chengdu, China. Engineering Geology 170: 24-32, https://doi.org/10.1016/j.enggeo.2013.12.006.

Zhang L and O'Kelly BC (2014) The principle of effective stress and triaxial compression testing of peat. Proceedings of the Institution of Civil Engineers - Geotechnical Engineering 167(1): 40-50, https://doi.org/10.1680/geng.12.00038.

\section{How can you contribute?}

To discuss this paper, please submit up to 500 words to the editor at journals@ice.org.uk. Your contribution will be forwarded to the author(s) for a reply and, if considered appropriate by the editorial board, it will be published as a discussion in a future issue of the journal. 